Archives de sciences sociales des religions

172 | octobre-décembre

Bulletin Bibliographique

\title{
Philippe Walter, Dictionnaire de mythologie arthurienne
}

Paris, Éditions Imago, 2014, 448 p.

Jean-Bruno Renard

\section{CpenEdition}

\section{Journals}

Édition électronique

URL : http://journals.openedition.org/assr/27486

DOI : $10.4000 /$ assr. 27486

ISSN : $1777-5825$

Éditeur

Éditions de l'EHESS

Édition imprimée

Date de publication : 1 octobre 2015

Pagination : 389

ISBN : 978-2-7132-2515-4

ISSN : 0335-5985

\section{Référence électronique}

Jean-Bruno Renard, «Philippe Walter, Dictionnaire de mythologie arthurienne », Archives de sciences sociales des religions [En ligne], 172 | octobre-décembre, mis en ligne le 22 juin 2016, consulté le 24 septembre 2020. URL : http://journals.openedition.org/assr/27486 ; DOI : https://doi.org/10.4000/ assr. 27486

Ce document a été généré automatiquement le 24 septembre 2020

(C) Archives de sciences sociales des religions 


\section{Philippe Walter, Dictionnaire de mythologie arthurienne}

Paris, Éditions Imago, 2014, 448 p.

Jean-Bruno Renard

\section{RÉFÉRENCE}

Philippe Walter, Dictionnaire de mythologie arthurienne, Paris, Éditions Imago, 2014, $448 \mathrm{p}$. 
1 Spécialiste de littérature française du Moyen Âge, Philippe Walter a dirigé la publication dans la «Bibliothèque de la Pléiade", sous le titre Le Livre du Graal (trois tomes, 2001, 2003, 2009), de tous les récits en ancien français appartenant au cycle dit du Roi Arthur et des Chevaliers de la Table ronde. À cette parfaite connaissance des textes français, $\mathrm{Ph}$. Walter ajoute celle de la littérature arthurienne en gallois, irlandais, breton, latin médiéval, et en diverses langues européennes (allemand, anglais, scandinave, etc.). Son Dictionnaire de mythologie arthurienne, dont il a rédigé les 593 notices, reflète ce large corpus et constitue donc l'outil de recherche le plus complet que l'on puisse trouver aujourd'hui sur le sujet.

2 L'ouvrage présente par ordre
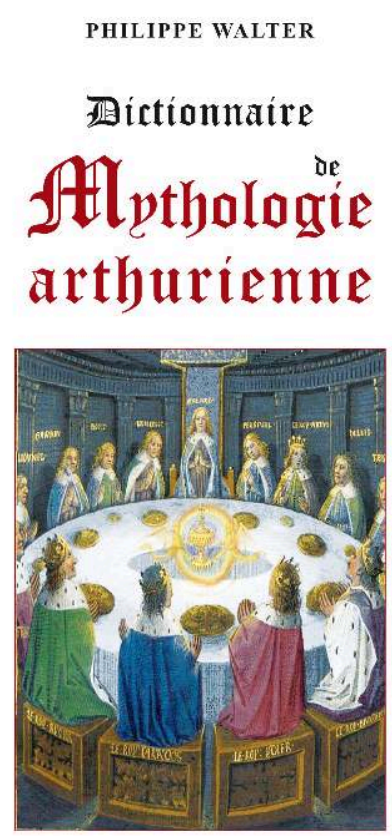

IMAGO alphabétique - depuis le chevalier-fée Aalardin jusqu'à l'ange déchu Zéphir - les personnages, les objets, les animaux, les lieux et plusieurs motifs narratifs du légendaire arthurien, plus quelques notions qui éclairent cette littérature. Citons des exemples de chacune de ces catégories. Les personnages les plus connus - comme le roi Arthur, l'enchanteur Merlin, la reine Guenièvre, les fées Morgane et Viviane, les chevaliers Lancelot, Perceval, Galaad - voisinent avec une multitude de personnages secondaires ou méconnus, tels que Agravain, Beau Couard, Daguenet, Lohot, Tidogalain ou Yonec. Des notices sont consacrées aux êtres fantastiques du Moyen Âge : fées, hommes sauvages, loups-garous, nains, ogres. Les objets possèdent une dimension magique, apportant aide ou châtiment aux protagonistes : ainsi le Graal, naturellement, ou Escalibor, l'épée $\mathrm{du}$ roi Arthur, mais aussi l'Anneau magique, le Cor enchanté, la Lance qui saigne, l'Oreiller magique, le Siège périlleux, la Table ronde. Des animaux exceptionnels proviennent de l'Autre Monde et y conduisent - Biche blanche, Blanc Cerf, le Cygne, le Dragon, la Licorne, le Sanglier - ou bien possèdent des pouvoirs merveilleux comme le cheval Bayart ou Husdent, le chien de Tristan. Les lieux sont associés au mystère ou au danger : l'Arbre illuminé, l'île d'Avalon, la fontaine de Barenton, la forêt de Brocéliande, le Château désert, le Pont de l'épée, la Terre gaste, le Val sans retour. Parmi les motifs étudiés, correspondant souvent à des épreuves auxquels sont soumis les chevaliers, mentionnons le Coup douloureux (ou Coup félon), coup de lance castrateur, le Fier baiser, donné à une créature repoussante, et l'Hôte hospitalier, qui se révèle être de l'Autre Monde. Plus théoriques, quelques notices définissent des notions utiles à la compréhension de la littérature arthurienne: Autre Monde, Conte, Coutume, Merveille, Métamorphose, Nom propre, Semblance (ou images analogiques), Souveraineté.

Si le Dictionnaire de mythologie arthurienne n'a pas la prétention d'être exhaustif, il est en revanche rigoureusement construit sur deux principes qui ont présidé au choix des items. Tout d'abord n'ont été retenus que les personnages, objets, lieux, etc., 
manifestant des « traits mythiques pertinents » (p. 15), c'est-à-dire qu'ils possèdent une dimension symbolique forte qui les rattache à des mythologies identifiées. Ensuite, en conformité avec la thèse de l'auteur, selon lequel «le roman arthurien est incompréhensible sans le recours à la mythologie celtique» (p.9), l'objectif de chaque notice est de « retrouver l'ancrage celtique de la notion visée » (p. 21). On est toutefois loin de la «celtomanie», puisque Philippe Walter montre aussi les sources mythologiques indo-européennes de nombre des items étudiés, ainsi que le grand mouvement de christianisation de ces motifs païens par le Moyen Âge, qui leur donne une nouvelle signification.

Pour l'étude des mythes - dans la ligne de Mircea Eliade et de Georges Dumézil Philippe Walter s'appuie sur l'exigence de la pluridisciplinarité : l'histoire, la philologie (notamment l'étymologie), l'ethnologie, le folklore, l'anthropologie culturelle, la sociologie, l'histoire des religions sont mobilisés pour fonder la mythologie comparée. Cette approche extrêmement féconde n'est possible qu'en raison de la grande érudition de l'auteur. Chaque notice est suivie de références bibliographiques, souvent méconnues, et de corrélats renvoyant à d'autres entrées du Dictionnaire.

5 Introduit par une préface de l'auteur qui éclaire d'un jour nouveau la littérature arthurienne, l'ouvrage est complété par une chronologie des récits arthuriens, de l'an 540 à l'an 1500 (p. 401-404), par un bilan des travaux d'éditions et de traductions de ces textes (p. 405-424) et par une riche bibliographie (p. 425-438). Tout concourt donc à faire de ce Dictionnaire, non seulement un "guide de lecture" pour la littérature arthurienne, comme le dit modestement l'auteur, mais aussi un outil de recherche indispensable pour qui s'intéresse à la mythologie. 